\title{
Economic growth volatility and resource curse: the role of financial development
}

\begin{abstract}
We assess whether well-developed financial systems can moderate the positive association between oil volatility and growth volatility. To this end, we follow Beck et alôs proposition (2006) and distinguish between two different kinds of volatility, that is, oil terms of trade volatility, which is referred to as real shock and inflation volatility, which is referred to as monetary shock. Using data from a sample of 63 oil-producing countries for the period of 1981-2010, the empirical analysis confirms a negative link between the volatility of oil terms of trade and growth. However, we also found weak evidence that financial development dampens the effect of oil terms of trade volatility.
\end{abstract}

Keyword: Resource curse; Financial development; Oil abundance dynamic panel data analysis 